\title{
Ética e organizações: narrativas e conflitos
}

\section{Ethics and organizations: narratives and conflicts}

\author{
Ética y organizaciones: narrativas y conflictos
}

\section{Paulo Nassar}

- $\quad$ Pós-doutor pela Libera Università di Lingue e Comunicazione (IULM) de Milão, Itália

- Doutor em Ciências da Comunicação pela Escola de Comunicações e Artes da Universidade de São Paulo (ECA-USP)

- $\quad$ Mestre em Relações Públicas pela ECA-USP

- Coordenador do Grupo de Estudos de Novas Narrativas (GENN) da ECA-USP

- $\quad$ Professor titular da ECA-USP desde 2017

- Professor do Programa de Pós-Graduação em Ciências da Comunicação (PPGCOM) da ECA-USP

- $\quad$ Diretor Presidente da Associação Brasileira de Comunicação Empresarial (Aberje)

- Pesquisador da British Academy

- E-mail: paulonassar@usp.br

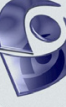

\section{Luiz Alberto de Farias}

- $\quad$ Pós-doutor em Comunicação na Universidade de Málaga (UMA), Espanha

- Doutor em Comunicação Ủniversidade de São Paulo (USP)

- Mestre em Comunicação e Mercado pela Faculdade Cásper Líbero (FCL)

- $\quad$ Especialista em Teoria da Comunicação pela FCL

- Professor do Programa de Pós-Graduação em Ciências da Comunicação (PPGCOM) da Escola de Comunicação e Artes da Universidade de São Paulo (ECA-USP).

- E-mail: lafarias@usp.br

Paulo Nassar e Luiz Alberto de Farias ministram no PPGCOM ECA-USP a disciplina Memórias Rituais: Narrativas da Experiência. 


\title{
Resumo
}

Este artigo faz uma reflexão sobre as relações entre ética, narrativas organizacionais e responsabilidade sócio-histórica, com base em um recorte conceitual e referências marcantes principalmente no campo da filosofia grega, inglesa e alemã, trazendo à tona os conflitos entre o discurso e as decisões e práticas organizacionais. Também projeta as tendências do capitalismo, uma vez que a ética se torna um ativo vital para a diferenciação das empresas no século XXI. E revela a pluralidade de visões éticas, sempre convergindo (e pondo em questão) os conceitos de bem e de felicidade.

\section{PALAVRAS-CHAVE: ÉTICA・NARRATIVAS ORGANIZACIONAIS・CAPITALISMO・MORAL・RESPONSABILIDADE SOCIAL.}

\begin{abstract}
This essay reflects on the relations between ethics, organizational narratives and socio-historical responsibility, based on a conceptual frame and references especially in the field of Greek, English and German philosophy, bringing to light the conflicts between discourse and organizational decisions and practices. It also projects the tendencies of capitalism, since ethics becomes a vital asset for the differentiation of businesses in the 21st century. And it reveals the plurality of ethical visions, always converging (and calling into question) the concepts of good and happiness.
\end{abstract}

KEYWORDS: ETHICS •ORGANIZATIONAL NARRATIVES • CAPITALISMO・MORALILY・SOCIAL RESPONSIBILITY.

\section{Resumen}

Este artículo hace una reflexión sobre las relaciones entre ética, narrativas organizacionales y responsabilidad socio-histórica, con base en un recorte conceptual y referencias marcadas principalmente en el campo de la filosofía griega, inglesa y alemana, trayendo a la luz los conflictos entre el discurso y las decisiones y prácticas organizacionales. También proyecta las tendencias del capitalismo, ya que la ética se convierte en un activo vital para la diferenciación de las empresas en el siglo XXI. Y revela la pluralidad de visiones éticas, siempre convergiendo (y poniendo en cuestión) los conceptos de bien y de felicidad. 
ANO 14 • NÚMERO 27 • 2º SEM. 2017 • ORGANICOM

ÉTICA E ORGANIZAÇÕES: NARRATIVAS E CONFLITOS

O que mais contribui para que um príncipe seja estimado é a realização de grandes empreendimentos e a prática de atos edificantes.

Maquiavel, O príncipe

\section{MULTIPLICIDADE DE FACES: UM MESMO CUIDADO COM O OUTRO}

A s narrativas sobre a ética têm infinitas faces. A filosofia grega sempre subordinou a ética ao bem comum e à vida feliz. E, sobretudo, a que a felicidade esteja ao alcance de todos. É com o tema da felicidade, aspiração universal, que Aristóteles, o herdeiro intelectual de Platão, inicia sua narrativa sobre a ética, apesar das dificuldades para defini-la. Existe uma pletora de outras narrativas: da ética da cidade justa de Platão à ética medieval do temor a Deus, da ética protestante da geração de riquezas, da ética do medo de Hobbes à ética da alegria de Spinoza, além da ética liberal de Locke, da ética do indivíduo de Kant, Schopenhauer e Nietzsche, a ética da felicidade de Bentham, a ética de classes de Marx e Engels e a ética da justiça de Rawls. Nas organizações, a chave da decifração ética - o sistema de decisões, a ação, os comportamentos, os juízos sobre o bem e o mal, o certo e o errado, o legítimo e o ilegítimo - é uma forma de ver. Uma "hibridez moral" que carrega em si "alto custo social" (Srour, 2012, capítulo 8, parágrafo 19). Ou seja, convivem às "turras", diz 0 autor Robert Henry Srour, referindo-se ao Brasil e à América Latina, uma ética idealista (a da integridade) e uma ética funcional (a do oportunismo) (Srour, 2012, capítulo 8, parágrafo 21). № Brasil, vivemos tempos de incerteza. A ética tem sido o caminho, embora sua aplicação prática, nas suas diferentes vertentes, seja complexa.

De qualquer forma, é preciso separar o que é ética e o que é moral: a ética é um corpo universal de conhecimento, enquanto a moral é relativa ao tempo e ao espaço. Os dois conceitos, porém, estão tão entrelaçados que não raro se confundem. Na Europa medieval, "todo negócio que visava o lucro era essencialmente imoral" porque toda a riqueza excedente deveria ser canalizada para a Igreja, responsável pela sua distribuição (Srour, 2012, capítulo 8, parágrafo 35). A legitimação do lucro só ocorreria com a reforma luterana e, mais tarde, com a Revolução Industrial. A lógica de maximização dos lucros, com seu extenso cortejo de repercussões negativas, por sua vez, já é considerada aética.

\section{COMO ARTICULAR O BEM COMUM}

Na origem, a ética pertencia à filosofia e procurava discutir a melhor maneira de viver. De modo que ser ético é pensar no outro. Para as organizações, é gerar benefícios de amplo espectro. Por essa razão, é que nas organizações

os truísmos se pautam pela razão ética. Em contrapartida, valores particularistas orientam práticas que são abusivas, porque obedecem a lógica da exclusão: 0 bem de uns causa mal a outros seres humanos (poucos se locupletam à custa de muitos). Por isso, é que o egoísmo e o parcialismo se pautam por razões antiéticas. (Srour, 2012, capítulo 8, parágrafo 76)

O bem, ensina Aristóteles, é aquilo a que todos aspiram, mas tem múltiplos fins: na medicina é a saúde, na construção naval, um navio, na estratégia, a vitória, e nas organizações, o lucro, e assim sucessivamente. Mas não se deve romantizar a narrativa da ética grega: ela aconselhava a fazer o mau aos inimigos e o bem aos amigos. Ulisses, na llíada, ao idealizar o cavalo de Tróia, leva 0 pressuposto de fazer o mau ao inimigo ao extremo. Ele via na morte do inimigo a sua morte, no destino do seu inimigo, o seu destino.

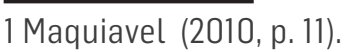


Por isso, era ardiloso. Homero "não decai" (Homero, 2003, p. 9), mas modernamente a ética ganhou novas narrativas: a ética humanística, a na web, a ecológica, a na política, nos negócios e, em especial, a ética nas corporações.

Como articular, por exemplo, os lucros das corporações com o bem comum? Como articular a narrativa ética em meio a tantas fraudes como as que se sucedem no país? É possível ser ético num ambiente não ético? Como fica uma organização que tem um forte discurso ético e, de repente, é envolvida em caso de corrupção?

Essas e outras questões perseguem as organizações, como uma sombra, desde o surgimento da Companhia das Índias Ocidentais, ou séculos antes, o capitalismo mercantil. Podemos demarcar linhas entre o universalismo e o particularismo, práticas consensuais e práticas abusivas, razão ética e racionalização ética. Aonde se poderia chegar? Às práticas de interesse geral, combinando o bem comum com o interesse geral? (Srour, 2012, capítulo 8, parágrafo 77).

É inevitável a questão: o mundo seria, em sua origem, ético e bem ordenado? Seria o homem guiado por alguma razão maligna ou pervertida (a narrativa bíblica ou rousseauniana) que promoveu a desordem? Ou o mundo, em sua origem, era desordenado e sem outra "ética" senão a do mais forte, e o homem só faz tentar ordená-lo? Como encontrar um ponto de equilíbrio entre a norma ética, o conflito e, principalmente, a prática?

Os pilares da ética em Aristóteles (1992), por exemplo, são a prudência, a virtude e o prazer. Estas se confundem com o modo de vida do homem, no sentido de humanidade, de ação, e conduzem à felicidade, enquanto "a vida dedicada ao dinheiro é um gênero violento" (Aristóteles, 2014, Livro l, 6, 1103a) e não traduz uma virtude. Por virtudes, entendam-se as virtudes intelectuais: sabedoria, inteligência prática, compreensão; e as virtudes morais: generosidade e temperança (Aristóteles, 2014, Livro l, 7, 1003a). Assim diz o filósofo grego:

Tudo que se produz por ignorância é não voluntário, porém é voluntário o que se dá com aflição e com arrependimento. Porém, a qualificação de "involuntário" não pode aplicar-se quando alguém ignora o que the convém, pois não é na ignorância que se dá a eleição da responsabilidade do ato involuntário (sim do vício), nem a ignorância em geral (Aristóteles, 2014, Livro III, 1, 1110b)²

Nesses casos, não deveria haver compaixão, nem perdão, pois não houve ignorância. Aristóteles viveu numa época parecida com a nossa. Se sofremos com a erosão de valores essenciais - a amizade, a fraternidade, a razão -, Atenas, no século IV a.C., estava desmoralizada com a derrota na guerra do Peloponeso; os gregos pregavam a lei do mais forte e a juventude sentia-se sem esperanças. Aristóteles thes acenou com a possibilidade de uma vida ética.

Simples, não? Se for abordado pelo viés da opinião, a questão política se reduz a uma tomada de posição mais ou menos argumentada. Mas se a questão for abordada sob o ângulo do poder político, então a complexidade ganha forma. Porque 0 exercício da ética está ligado ao sistema de valores e, em síntese, à governança das organizações para o bem da sociedade.

\section{AÉTICA DA RIQUEZA}

As discussões em torno da ética acompanham o desenvolvimento da sociedade. Na Roma Antiga, não era ético ter escravos. 0 escravo não passava de um instrumento. Era simples extensão dos seus donos. Não era ninguém. Era fonte de riquezas e poder.

2 Os autores em livre tradução. 
ANO 14 • NÚMERO 27 • 2º SEM. 2017 • ORGANICOM

ÉTICA E ORGANIZAÇÕES: NARRATIVAS E CONFLITOS

No início do Renascimento, o cenário irá mudar, e radicalmente: Leonardo Bruni, intelectual de múltiplos saberes, que se fundamenta em Aristóteles, Cícero e Políbio, não para defender o escravismo, mas para fazer com que a ideia da riqueza deixasse de ser tema de polêmica e temor de perda da antiga virtù romana - a capacidade de mudar o destino - para converter-se em uma questão que podia ser resolvida por meio da ética aristotélica. E, assim, os bens materiais passaram a ser incorporados às virtudes ativas.

Ele afirma, como se tentasse sintetizar a preeminência da vida ativa em oposição à vida contemplativa, que a força das instituições e da educação é que determinam a realidade dos valores republicanos. Seria esse o sentido profundo, na República, da ética. Seria a ética o caminho seguro para a acumulação de riquezas?

Como Aristóteles, Leonardo Bruni (2007) considera a riqueza e os bens materiais como uma virtù ativa. 0 prefácio de Economia (obra aristotélica na concepção, mas erroneamente atribuída a Aristóteles), que ele traduziu para Cosme de Médici, enfatiza que as divitiae destacam seus proprietários e lhes conferem "a capacidade de praticar suas virtudes". Faz o elogio da riqueza herdada como forma de tornar a vida mais fácil, ser magnânimo e liberal, elevando-se na dignidade da República. Tem, porém, o cuidado de condenar o apetite ilimitado pela riqueza. A tradução de Economia foi vastamente divulgada; Bruni, amplamente criticado.

Bruni defendeu-se recorrendo a uma nova interpretação de Platão e Aristóteles. "Em tanto que a alma, apesar de que é muito mais valiosa, necessita do corpo a fim de que viva o ser humano, os bens da alma podem ser muito mais valiosos e, ainda assim, necessitam de bens materiais e corporais para produzir a felicidade", conforme citado por Hans Baron (1993, p. 141-142). Na sua argumentação, Bruni rebatia a doutrina estoica que, no seu entender, estava fora do alcance do ser humano, salvo para aqueles que se tivessem transformado em "blocos sem alma", despojados de toda a sua humanidade. Sua rigidez de princípios amesquinhava os corações. Segundo ele, a doutrina de Aristóteles, ao contrário, faz "humanos aos homens" (Baron, 1993, p. 141-142).

O humanista Leonardo Bruni recorre com frequência à Ética a Nicômaco. Procura alinhar as necessidades do corpo, como a alimentação, às necessidades da alma, como a contemplação, mas não recua da tese principal: "A condição prévia da liberdade é o dinheiro: para alcançar a justiça são necessárias as propriedades; para ter valor é necessária a força" (Baron, 1993, p. 199).

A guinada, com Bruni, foi notável. Com a revitalização da ética cívica de Aristóteles, a frugalidade de Cesar e de seus soldados, que se contentavam com farinha, manteiga e água, no dizer de Boccaccio, tornou-se alvo de ironias e ácidas críticas.

A explicação para a existência desse culto a pobreza estava na tirania que varrera a liberdade da antiga república romana (Baron, 1993). Rompido o dogma estoico e religioso da pobreza, a influência do aristotelismo cívico projetou-se pelos centros humanísticos de toda a Itália. Com ele, a Renascença começa a florescer sob o signo do nascente capitalismo e a ideia de República irrompe como um símbolo de liberdades públicas e, acima de tudo, como liberdade de empreender que, na contracorrente do humanismo, vai paulatinamente limitando a participação da vida pública a uns poucos cidadãos possuidores de riquezas.

É nesse contexto de reflexão em torno da circularidade da história que se destaca a personalidade e a obra de Leonardo Bruni. Mas as contradições em torno da pobreza não desapareceram e continuaram a se acirrar. Se antes de Bruni, os quiliastas invadiam cidades na Europa na expectativa de promover a igualdade entre os homens, no século XVI, na Alemanha, explodiu a primeira revolta armada camponesa, esta liderada por Thomas Müntzer, antigo companheiro de Martinho Lutero, resoluto a derrubar os nobres e tomar as terras para distribuí-las. Foi supliciado e enforcado. Mas a revolução luterana e sua visão 
ética quanto à igualdade dos homens perante Deus renderia frutos. Daria origem às revoluções Inglesa, Francesa e, inclusive, à Revolução Russa, que nasceu de uma corrente da Revolução Francesa. A utopia comunista, que inaugura a narrativa da ética de classes, que floresceu com Karl Marx. 0 escravismo foi frontalmente condenado.

A utopia veio para ficar. Primeiro, pela crença do poder das ideias. A seguir, pelo poder da Revolução. A força das relações de produção e as forças sociais que elas portam fizeram a história dos utopistas, o comunismo científico e todo o extenso cortejo de lutas sociais que já existiam nos tempos de Leonardo Bruni e, evidentemente, não desapareceram com a valorização das riquezas.

\section{ÉTICA PRÁTICA}

O que seria uma ética prática? Inviabiliza-se num mundo dominado pela ilusão, pela falsificação e pela "defraudação", mas é viável num mundo de solidariedade das forças sociais (Bloch, 2006a, p. 426). É a tese de Ernest Bloch e seu princípio esperança.

Da condenação dos valores capitalistas, em Bloch, derivam a rejeição ao neokantismo doutrinário que ele definia como "fantasia objetiva" à época em que, aos 22 anos, formulou o conceito de "ainda-não-consciente" e, também, conceitos como "ainda-não", "latência", "tendência" e "utopia" (Münster, 1997, p. 59-60). Foi um processo crítico ao neokantismo iniciado nas duas primeiras décadas do século XX, mas que, por meio de Kant, abriu-lhe os olhos para a tese da antecipação do futuro.

Se a doutrinação do neokantismo fomentava o embate autoritário contra a compreensão da história, Kant $(2003,2005,2010)$ acendeu a fagulha do pensamento ético que une a consciência contra a opressão na ética do compromisso (a lei) e na ética da responsabilidade (o humanismo). A esse respeito, era necessária, para Bloch, uma ação prática, ampliando o tema da ética para todos os homens, fazendo do amanhã e do mundo a medida a modelar pela experiência.

Essa tese supera a ética iluminista que conduz ao cognitivismo, o individualismo e universalismo (Rouanet, 1990, p. 149). Sim, a ética blochiana é cognitivista, porque prescinde da religião como guia moral e, igualmente, é universalista, por entender que o respeito à humanidade é um valor universal, mas não é individualista no que se refere a colocar 0 homem acima da coletividade e das suas obrigações com relação à pólis. 0 homem ético, além das obrigações comuns, não orientadas para a centralidade da autorrealização do indivíduo, o hedonismo e o egoísmo, é aquele que sonha com o futuro.

Em Bloch, o indivíduo não é um átomo isolado, um ser soberano capaz de se sobrepor às leis e estabelecer critérios soberanos do bem e do mal. 0 homem é o universal, mas o procedimento de universalidade começa pela organização social. 0 processo não mais conduziria à dicotomia entre a natureza e o costume, mas para um mundo em que o eudemonismo fosse comum a todos e a eticidade fosse a consciência moral solidária.

Contra o individualismo e as éticas discursiva, normativa e do individualismo absoluto, a ética socialista da igualdade e do progresso coletivo deveria ser levada à prática para criar uma sociedade humana. Uma filosofia ética de liberdade, com 0 propósito de criar uma sociedade sem classes e criar condições para a existência do humano-universal. Em Bloch, nada existe de ingênuo ou meramente sonhador na defesa desse caminho. A começar que ele não é eurocêntrico, isto é, não pensa o mundo a partir da Europa, mas com o horizonte universal. Conhecimento, compreensão e engajamento do filósofo na libertação humana estão inter-relacionados, sendo mobilizador para a reflexão dialética sobre "o ainda-não-ser, sobre 0 
Novo"3. Nada converge para a restauração repetitiva do mesmo. Tudo se volta para a revolução e à construção do mundo sob o signo da liberdade, igualdade e fraternidade.

Em The spirit of utopia (2000), em Traces (1968) e em O princípio esperança (2005, 2006a, 2006b), há persistente fascínio pela ética kantiana. Mas a ética blochiana inclina-se para o que favorece a libertação do homem. É uma ética da "ação desinteressada". Permeia a ideia do apocalipse, que varreria do mundo o capitalismo e faria o homem despertar para a "mediocridade" imposta por "medíocre", que é o pensar apenas em si mesmo (Bloch, 2000, p. 235).

Em Traces, Bloch (1968), ao demarcar as fronteiras do seu pensamento da ética de Kant, compara o homem a uma criança que, no ventre da mãe, possui seus órgãos formados, mas que ainda não desenvolveu habilidades morais. Volta ao tema em O princípio esperançaao sublinhar que, no homem, "o conteúdo da esperança ainda é menor que o anseio" (Bloch, 2006b, p. 462).

A sua utopia amplifica o limite da realidade até o ser possível. Os homens não são o que são, mas o que podem ser. A práxis e a ética não são zonas autônomas. Estão interligadas pela vontade de mudança. Altera-se, então, por completo, o princípio ético burguês: ética é transformação. Seu paradigma inicial pode se assentar na ética da responsabilidade kantiana, mas se desenvolve na ética de um mundo novo, um homem novo. É uma ética que alargaria o mundo humano para a luz e faria a vida coincidir com a imanência humanística no sentido "radicalmente progressista", tornando "o desenvolvimento da riqueza da natureza humana como fim em si mesmo" (Bloch, 2006b, p. 372).

A sua reorganização das Teses de Marx sobre Feuerbach tem essa perspectiva. Na Tese 2, o pensamento escapa da "generalidade" e da "abstração" para se fixar nas relações entre teoria e prática, o que lembra, como ressalta Bloch, os estoicos, que tinham a lógica como "mero muro, a física como mera árvore e a ética como fruta" (Bloch, 2005, p. 265). 0 ato de pensar e agir incentiva o homem a transformar o mundo (Tese 2) e fazer da ética o cerne dessa transformação.

Além da riqueza interior do homem como fim, não como meio, a descoberta de Kant, por Bloch, ocorre na Universidade de Würzburgo, onde, por dois anos, Bloch estudou profundamente Kant e a epistemologia pós e neokantiana ${ }^{4}$. Isso o impulsionou à "esperança ativa, distinta de toda a confiança cega e passiva no futuro" (Münster, 2001, p. 278).

É com a disposição de intervir no mundo que Bloch propõe uma ética revolucionária, tema que, por estranho que possa parecer, encontra-se "ausente do pensamento filosófico contemporâneo e também do marxismo" (2005, p. 269, tradução nossa) $)^{5}$, mas presente na "dimensão ética dos anos 1920" e nos "últimos escritos de Rosa Luxemburgo", em que se encontram colocadas as palavras "ideal" e "socialismo" (Palmier, 1986, p. 262).

Em Bloch, a ética é sobre o repensar da religião, da tecnologia, das relações de produção e o repensar do próprio homem. Não comporta ilusões. Não é uma ética normativa. Desenrola-se nas categorias do ainda-não-consciente, da totalidade do ser e no pressuposto filosófico do mundo como processo. É a ética que associa a negação de Deus e do destino à autodeterminação humana e ao futuro. É uma escolha, tendo como objetivo final a felicidade humana e a convivência coletiva. Fundamentase na categoria da possibilidade. Envolve a dialética do ainda-não e o entusiasmo do dever-ser. Explica a simpatia de Bloch

3 Cf. Marxismo e libertação, de Antonio Rufino Vieira (2010, p. 112), no que se refere aos vínculos do pensamento blochiano e à Filosofia de Libertação latino-americana: "A superação da alienação é base real para que o homem se realize enquanto liberdade. Como o conceito de homem não é abstrato, mas concreto, ele aplica-se diretamente às classes sociais, de modo especial àquelas que têm o seu ser negado, subsumido pelo capital dependente. A Filosofia, nos países dominados, portanto, é chamada para outro compromisso, exigindo de si um novo estatuto epistemológico, uma nova atitude política, um novo conceito de homem".

4 Nas universidades alemãs, entre 1870 e 1914, predominava o neokantismo e o pensamento oficial representado por Hegel. Também predominava a influência de Nietzsche, além da mística alemã de Jacob Boehme e Eckhart de Hochheim, mais conhecido como Mestre Eckhart (Münster, 1993).

5 "Il est étrange de constater que ce thème est aujourd'hui a peu présent de la philosophie contemporaine aussi bien que du marxisme". 
ANO 14 • NÚMERO 27 • 2º SEM. 2017 • ORGANICOM

ÉTICA E ORGANIZAÇÕES: NARRATIVAS E CONFLITOS

pelo romantismo revolucionário e pelo poder dialético da Utopia de More. Completa-se com a totalidade do ser e a conexão entre todas as coisas.

\section{DA ÉTICA RETÓRICA À ÉTICA TRANSFORMADORA}

A maior parte do século passado foi de embate entre as narrativas de utopia e as narrativas voltadas para os ganhos de produtividade e competitividade. Os temas centrais das narrativas organizacionais eram o desenvolvimento, os empregos, os investimentos, os mercados e a tecnologia; para a sociedade, a política era pedra de toque e em meio às esquerdas, "o homem novo". 0 tema da ética era naturalizado, como se ela fosse produzida por geração espontânea e não exigisse a educação do homem.

A realidade revelou-se cruel. Desde a Grécia Antiga creditavam-se as transgressões, com maior ou menor intensidade, à falta de consciência. Não era bem assim na prática, mas esquecia-se a prática. Era cômodo. No contexto das organizações, não se precisava mexer no modelo de negócios, fundamentado no "fetiche da mercadoria" (Sennett, 2014, p. 214).

Com a queda do Muro de Berlim, não só a ideia do "homem novo" se liquefez, como se instalou uma crise ética sem precedentes no mundo ocidental. Nas redes sociais, com a velocidade que se imprimiu à comunicação, a narrativa ética tornou-se quase sempre uma peça de retórica dissolvida no choque com a realidade social e organizacional.

Em O homem da companhia, Anthony Sampson (1996, p. 341) define as companhias como um "campo de batalha global". Referia-se aos anos 1990 e ao embate entre as empresas americanas e japonesas, com impasses de ambos os lados - em particular o fim da lealdade por parte de empregados e empregadores - vindo à tona pela primeira vez em quatro décadas. Testemunha da nova realidade ética era a onda de fusões e incorporações, locus patrimonial sem compromisso com identidades, missões, visões e valores ancorados na tradição dos negócios.

0 cenário era de incerteza e a Europa não chegava a ser exceção. "Os executivos europeus ainda estavam mergulhados em suas culturas e estilos nacionais separados, formados por sistemas educacionais, cada um com suas especialidades e limitações" (Sampson, 1996, p. 354). Era preciso se tornar mais profissionais, seguindo a trilha aberta pelas empresas alemãs e inglesas, desde os anos 1950. Mas as versões do capitalismo continuavam muito diferentes e nada indicava que fosse haver mudanças expressivas (Sampson, 1996, p. 354-358).

Agora, as pressões se avolumam e as narrativas adicionam o ingrediente da ética como exigência. Segundo Srour (2012, Apresentação, parágrafo 5), "ganha corpo a cidadania organizacional". Isso é a era da informação que serve de base à Revolução digital, um momento tão inédito quanto foi a era da máquina, nos dois séculos da Revolução Industrial. Revolução digital que nasceu, embora não visível por toda a parte, mais liberal, mais democrática, com relações corporativas "autônomas e comunitárias e, sobretudo, capitalistas sociais" (Srour, 2012, Introdução, parágrafo 13).

Nesse novo tipo de capitalismo, o excedente econômico é partilhado por salários indiretos, remuneração variável, participação nos lucros, investimentos em projetos comunitários que fortalecem o terceiro setor, ou se instala sob a forma de parcerias entre o setor privado e o setor público. E a tendência seria "superar o antigo capitalismo excludente" (Srour, 2012, Introdução, parágrafo 15).

Celebra-se, assim, a matriz libertária, pelo menos no Primeiro Mundo e no plano retórico. "Um destaque especial cabe à teoria ética da responsabilidade, que se funda na análise de risco com vistas à produção de resultados coletivamente benéficos 
(racionalidade teleológica), em contraste com a teoria ética da convicção, que faz da conformidade aos deveres sua regra de ouro" (Srour, 2012, Introdução, parágrafo 18). A ética tornou-se um diferencial competitivo no mercado, como são a qualidade dos bens e serviços e as novas tecnologias.

O que significa isso? Que à mecânica capitalista foi incorporada uma nova chave-mestra: as empresas deixam de se orientar apenas pelo lucro, ainda que este fosse determinante, e passam a guiar-se, de modo indissociável, pela conduta da responsabilidade social (Srour, 2012, capítulo 2, parágrafo 37). Fato é que não se define mais uma empresa apenas pelo valor dos seus ativos materiais, mas contabiliza-se também o conceito de responsabilidade social, de responsabilidade histórica ${ }^{6}$, que reveste 0 capitalismo de um princípio associativo e distributivista.

A extensa rede de públicos estratégicos - dentre eles, a imprensa, autoridades, sindicatos, empregados, organizações não governamentais, clientes, investidores e as comunidades diretamente atingidas ou interessadas pelas atividades e operações organizacionais - está cada vez mais atenta à qualidade da identidade das empresas, construída a partir da memória e história relacional dessas organizações, mediadas com base em suas narrativas da experiência com esses públicos.

São narrativas alicerçadas na memória e na história, que expressam os fatos ligados à competência, à legalidade e à legitimidade organizacionais, fundamentais para a concessão, pela sociedade, do licenciamento social para o funcionamento organizacional. Narrativas que exigem, por parte das organizações, compromissos que transcendam o contexto dos acontecimentos das linhas de produção, dos escritórios, dos pontos de venda, e colocam suas políticas, seus planejamentos e suas ações também alinhadas com as transformações sociais, do Estado, da política e da democracia, sob o pano de fundo da globalização e das novas tecnologias da informação, em que se criam novas significações em um ambiente de ágora digital. Nesse contexto social, político e tecnológico, em que a responsabilidade histórica das empresas e instituições é examinada pela sociedade e os seus públicos, inaugura-se um extenso cortejo de impactos sobre a identidade organizacional.

Em outras palavras, deve-se observar, diante dessas exigências da sociedade e do mercado, que a identidade organizacional esteja sedimentada o suficiente para que sejam levadas à prática mudanças que sintonizem as empresas com as amplas transformações da ecologia social, cultural e econômica a que pertencem. Esse cenário remete as empresas para a responsabilidade com a qualidade de vida nas comunidades onde essas organizações têm algum tipo de relacionamento. São questões prementes e urgentes, necessárias à construção de um ambiente que supera a mera retórica, comprometendo-se com narrativas éticas transformadoras.

\section{CONSIDERAÇÕES FINAIS}

0 que se pode inferir no atual cenário de mudanças é que, a julgar pelas tendências, sejam elas dominantes ou não, uma parte importante do capitalismo luta para se tornar civilizado ${ }^{7}$. A sociedade se torna mais e mais participante, e tudo que não soa ético se desmancha no ar.

Pode-se argumentar que se trata de uma visão idealista, mas a mera valorização da ética já é uma virtude. E significa que 0 egoísmo já não é tão abundante e o cuidado com o cidadão e com o meta-humano já não é mais tão escasso (Nassar; Janine Ribeiro; Guttilla, 2007, p.15).

6 Tal conceito desenvolvido por Paulo Nassar tem natureza sistêmica e cobre todo o período de existência da organização, cuja credibilidade (e identidade) decorre do cumprimento de suas responsabilidades numa perspectiva histórica, que vai dos feitos do passado às promessas para o futuro (Camargo; Goulart, 2015; Nassar, 2012).

$7 \mathrm{Um}$ bom exemplo que ancora essa afirmativa é o documento on-line Desculpe, a Odebrecht errou (Odebrecht, 2016). 
Há uma ética do real em ascensão. 0 desejo de levá-la à prática pode vir a ser um componente para uma ação correta. É como se 0 valor ético fosse um imperativo a ser protegido da devastação do real, da "morte da família", da "morte da escola", da "morte de Deus", da "morte do trabalho" e dos valores em tensão com as visões relativistas.

É como se a utopia ética estivesse sendo empurrada cada vez mais longe, a despeito da ameaça permanente do retorno à barbárie. A ética nesses novos tempos também é sinônimo de solidariedade e de uma polis igualmente unida pela solidariedade. Será que as empresas e instituições estão preparadas para essa nova leitura do tempo? Para narrativas reais? 0 futuro dirá.

\section{REFERÊNCIAS}

ARISTÓTELES. Ética a Nicômaco. Brasília: UnB, 1992.

Ética a Nicómaco. Trad. de José Luiz Calvo Martínez. Madrid: Alianza Editorial, 2014.

BARON, Hans. En busca del humanismo cívico florentino. Trad. de Miguel Abelardo Camacho Ocampo. Ciudad de México: Fondo de Cultura Económica, 1993.

BLOCH, Ernest. Traces. Paris: Gallimard, 1968.

The spirit of utopia. Trad. de Antony A. Nassar. Redwood City: Stanford University, 2000.

O princípio esperança. Trad. de Nélio Schneider. Rio de Janeiro: Contraponto, 2005. v. 1.

O princípio esperança. Trad. de Werner Fuchs. Rio de Janeiro: Contraponto, 2006a. v. 2.

. O princípio esperança. Trad. de Werner Fuchs. Rio de Janeiro: Contraponto, 2006b.v. 3.

BRUNI, Leonardo. Memoirs. In: History of the Florentine people. London: Harvard, 2007, v. 3.

CAMARGO, Ana Maria; GOULART, Silvana. Centros de memória: uma proposta de definição. São Paulo: Sesc Edições, 2015.

HOMERO. /líada. Trad. de Haroldo de Campos. São Paulo: ARX, 2003.

KANT, Immanuel. Crítica da razão prática. Trad. de Valério Rohden. São Paulo: Martins Fontes, 2003.

The metaphysical elements of ethics. Trad. de Thomas Kingsmill Abbott. State College: Penn State University Press, 2005.

The critique of pure reason. Trad. de J. M. D. Meiklojohn. State College: Penn State University Press, 2010.

MAQUIAVEL, Nicolau. O príncipe. Trad. de Maurício Santana Dias. São Paulo: Penguin/Companhia das Letras, 2010.

MÜNSTER, Arno. Ernst Bloch: filosofia da práxis e utopia concreta. São Paulo: Unesp, 1993. 
ANO 14 • NÚMERO 27 • 2오. SEM. 2017 • ORGANICOM

Utopia, messianismo e apocalipse nas primeiras obras de Ernst Bloch. Trad. de Flávio Beno Siebeneichler. São Paulo: Unesp, 1997.

L'utopie concrète d'Ernst Bloch: une biographie. Paris: Éditions Kimé, 2001.

NASSAR, Paulo. Relações públicas na construção da responsabilidade histórica e no resgate da memória institucional das organizações. 3. ed. São Caetano do Sul: Difusão, 2012.

NASSAR, Paulo; JANINE RIBEIRO, Renato; GUTTILLA, Rodolfo W. (Orgs.) A comunicação organizacional frente ao seu tempo: missão, visão e valores Aberje. São Paulo: Aberje Editorial, 2007.

ODEBRECHT. Comunicação. Releases. Desculpe, a Odebrecht errou. 1 dez. 2016. Disponível em: <https://goo.gl/R4yG8m>. Acesso em: 18 nov. 2017.

PALMIER, Jean-Michel. En reliant L'Ésprit de l'utopie ou Priére pour un bon usage d'Ernst Bloch. In: GOETHE INSTITUT. Réification et utopie: Ernst Bloch and György Lukács un siècle après. 1985, Arles. Actes du colloque Goethe Institut... Arles: Actes Sud, 1986.

ROUANET, Sérgio Paulo. As razões do lluminismo. Rio de Janeiro: Companhia das Letras, 1990.

SAMPSON, Anthony. O homem da companhia. Trad. de Pedro Maia Soares. São Paulo: Companhia das Letras, 1996.

SENNETT, Ricardo. O declínio do homem público. Trad. de Lygia Araújo Watanabe. São Paulo: Companhia das Letras, 2014. SROUR, Robert Henry. Poder, cultura e ética nas organizações. Rio de Janeiro: Elsevier, 2012.

VIEIRA, Antonio Rufino. Marxismo e libertação: estudos sobre Ernest Bloch e Enrique Dussel. São Leopoldo: Nova Harmonia, 2010.

Texto recebido em 06.12.2017 e aprovado em 18.12.2017. 